University of Nebraska - Lincoln

DigitalCommons@University of Nebraska - Lincoln

\title{
Methodologies for simulating impacts of climate change on crop production
}

Jeffrey W. White

$A L A R C$, USDA-ARS, jeffrey.white@ars.usda.gov

Gerrit Hoogenboom

University of Georgia

Bruce A. Kimball

USDA-ARS, bruce.kimball@ars.usda.gov

Gerard W. Wall

ALARC, USDA-ARS

Follow this and additional works at: https://digitalcommons.unl.edu/usdaarsfacpub

Part of the Agricultural Science Commons

White, Jeffrey W.; Hoogenboom, Gerrit; Kimball, Bruce A.; and Wall, Gerard W., "Methodologies for simulating impacts of climate change on crop production" (2011). Publications from USDA-ARS / UNL Faculty. 886.

https://digitalcommons.unl.edu/usdaarsfacpub/886

This Article is brought to you for free and open access by the U.S. Department of Agriculture: Agricultural Research Service, Lincoln, Nebraska at DigitalCommons@University of Nebraska - Lincoln. It has been accepted for inclusion in Publications from USDA-ARS / UNL Faculty by an authorized administrator of DigitalCommons@University of Nebraska - Lincoln. 


\title{
Methodologies for simulating impacts of climate change on crop production
}

\author{
Jeffrey W. White ${ }^{\mathrm{a}, *}$, Gerrit Hoogenboom ${ }^{\mathrm{b}, 1}$, Bruce A. Kimball ${ }^{\mathrm{a}}$, Gerard W. Wall ${ }^{\mathrm{a}}$ \\ a ALARC, USDA-ARS, 21881 North Cardon Lane, Maricopa, AZ 85138, United States \\ b Department of Biological and Agricultural Engineering, University of Georgia, Griffin, GA 30223-1797, United States
}

\section{A R T I C L E I N F O}

\section{Article history:}

Received 14 September 2010

Received in revised form 29 June 2011

Accepted 4 July 2011

\section{Keywords:}

Adaptation, Agricultural impacts, Climate

change, Crop growth simulation, Global

warming, Modeling

\begin{abstract}
A B S T R A C T
Ecophysiological models are widely used to forecast potential impacts of climate change on future agricultural productivity and to examine options for adaptation by local stakeholders and policy makers. However, protocols followed in such assessments vary to such an extent that they constrain cross-study syntheses and increase the potential for bias in projected impacts. We reviewed 221 peer-reviewed papers that used crop simulation models to examine diverse aspects of how climate change might affect agricultural systems. Six subject areas were examined: target crops and regions; the crop model(s) used and their characteristics; sources and application of data on $\left[\mathrm{CO}_{2}\right]$ and climate; impact parameters evaluated; assessment of variability or risk; and adaptation strategies. Wheat, maize, soybean and rice were considered in approximately 170 papers. The USA ( 55 papers) and Europe (64 papers) were the dominant regions studied. The most frequent approach used to simulate response to $\mathrm{CO}_{2}$ involved adjusting daily radiation use efficiency (RUE) and transpiration, precluding consideration of the interacting effects of $\mathrm{CO}_{2}$, stomatal conductance and canopy temperature, which are expected to exacerbate effects of global warming. The assumed baseline $\left[\mathrm{CO}_{2}\right]$ typically corresponded to conditions $10-30$ years earlier than the date the paper was accepted, exaggerating the relative impacts of increased $\left[\mathrm{CO}_{2}\right]$. Due in part to the diverse scenarios for increases in greenhouse gas emissions, assumed future $\left[\mathrm{CO}_{2}\right]$ also varied greatly, further complicating comparisons among studies. Papers considering adaptation predominantly examined changes in planting dates and cultivars; only 20 papers tested different tillage practices or crop rotations. Risk was quantified in over half the papers, mainly in relation to variability in yield or effects of water deficits, but the limited consideration of other factors affecting risk beside climate change per se suggests that impacts of climate change were overestimated relative to background variability. A coordinated crop, climate and soil data resource would allow researchers to focus on underlying science. More extensive model intercomparison, facilitated by modular software, should strengthen the biological realism of predictions and clarify the limits of our ability to forecast agricultural impacts of climate change on crop production and associated food security as well as to evaluate potential for adaptation.
\end{abstract}

Published by Elsevier B.V.

\section{Introduction}

Ecophysiological models are widely used to simulate the potential impacts of environmental factors on agricultural and natural ecosystems. An especially active area of application is in research on the potential impacts of climate change, and simulations have been a major data source for Intergovernmental Panel on Climate Change (IPCC) assessments for agriculture (Gitay et al., 2001; Easterling et al., 2007). As early as the second IPCC assessment report, extensive use was made of results from crop growth modeling (Reilly et al., 1996). Ignoring the contentious topic of whether a given

\footnotetext{
* Corresponding author. Tel.: +1 5203166368.

E-mail address: jeffrey.white@ars.usda.gov (J.W. White).

1 Current address: AgWeatherNet, Washington State University, Prosser, WA 99350-8694, United States.
}

model provides realistic simulations for a given environment and suite of management practices, the mechanics of simulating crop responses to specific changes in temperature, $\mathrm{CO}_{2}$ or other abiotic factors may appear straightforward: one provides the model with initial field conditions (e.g., for soil moisture and nitrogen status), crop information (cultivar characteristics, planting arrangement, and fertilization and irrigation, if any), and the daily weather and $\left[\mathrm{CO}_{2}\right]$ data corresponding to the historic, current or future scenarios of interest; the simulation is then run, and the outputs are compared to those of other simulations where different initial conditions, management practices, or weather and $\left[\mathrm{CO}_{2}\right]$ scenarios were used. In practice, the process involves numerous issues of data availability and quality and of scaling from global climate change data to the plot scale, where crop models typically operate. Furthermore, models are limited in the number of processes they consider, contrasting with the real-world complexity of cropping systems. 
In conducting a preliminary review of papers that examined the simulated effects of climate change and increased $\left[\mathrm{CO}_{2}\right]$ on agriculture, we encountered such a large diversity in how simulations were conducted and reported that efficient comparison of impact across studies appeared difficult at best. Of particular concern was that the differences among protocols seemed to introduce biases that were likely to be overlooked in peer review. Diversity in methodology is expected for an active and controversial research domain, but over time, a consensus on protocols should emerge. Simulation studies need to be credible, replicable, and readily compared among one another as the results ultimately could affect the livelihoods of many stakeholders. Comparability is especially relevant for climate change research where results may guide major decisions on policy or investments, yet the few options for fieldscale assessments are costly.

For studies of climate change impacts on agroecosystems, methodological issues of concern include how the crop models are initially evaluated and selected, how geographic regions are sampled, how outputs of general circulation models (GCMs) or regional climate models (RCMs) are down-scaled to locations or sub-regions, and whether adaptations such as changes in planting dates or cultivars are considered. Assessments of potential impacts may consider only economic yield, or they may examine plant traits, resource use, environmental parameters, or socio-economic analyses, which might extend to projections of regional food security and long-term sustainability of small-holder farms.

The first major assessment of climate change impacts appears to be the 1975 Climate Impact Assessment Project, which the US Dept. of Transportation commissioned to estimate impacts of emissions from supersonic aircraft (Katz, 1977). Critiques of methods for predicting crop responses to climate change and increased $\left[\mathrm{CO}_{2}\right]$ date to at least 1977 when Katz (1977) noted that regression models used to predict crop yields had limitations relating to assumed linearity of effects and to lack of independence among predictor variables. Smit et al. (1988) reviewed 17 papers that used different modeling approaches. The introductory paper of the 1993 series on the MINK ("Missouri, Iowa, Nebraska, Kansas") project (Rosenberg et al., 1993) provided many useful observations on methodologies. Tubiello and Ewert (2002) reviewed crop modeling studies that were conducted from 1995 to 2002 and found that approximately $20 \%$ of studies dealt with climate change. Of those papers, about half considered responses to $\left[\mathrm{CO}_{2}\right]$. The authors cited various examples where mechanisms appeared to be oversimplified, and they argued that the scarcity of field-scale studies of crop response to $\left[\mathrm{CO}_{2}\right]$ limited model testing, a theme still widely voiced (Easterling et al., 2007; Ainsworth et al., 2008). Other reviews concerned with modeling impacts of climate change include Iglesias et al. (1996), Mendelsohn and Dinar (1999), Motha and Baier(2005), Timsina and Humphreys (2006), Rosenzweig and Tubiello (2007), Challinor et al. (2009) and Soussana et al. (2010). Common themes among the reviews have been the need to strengthen the physiological assumptions of models, especially with respect to heat stress, responses to $\left[\mathrm{CO}_{2}\right]$ and genetic diversity, the need for more attention to sources of uncertainty, and the desirability of having standard protocols for modeling impacts.

The goal of our study was to analyze protocols used to simulate the impacts of climate change in order to identify potential sources of bias or uncertainty and ultimately, to suggest avenues for improving assessments. A second objective was to examine what level of physiological and agronomic complexity was represented in the models that are currently used in climate change assessments in order to understand potential limitations in their application and thus suggest priority areas for model development, testing, or improvement. To avoid potential bias in interpretation of findings, we used a structured survey designed to address the objectives of the paper. The approach was used successfully in a previous
Table 1

Tabulation of papers considered for evaluation.

\begin{tabular}{|c|c|}
\hline Source or criterion for removal & Number of papers \\
\hline All citations from initial search of CAB Abstracts ${ }^{a}$ & 628 \\
\hline $\begin{array}{l}\text { Non-journal papers (book chapters, conference } \\
\text { proceedings, annual reports, etc.) }\end{array}$ & -139 \\
\hline Papers unavailable through Internet sources & -23 \\
\hline $\begin{array}{l}\text { Papers in languages other than English, French, } \\
\text { Portuguese or Spanish }\end{array}$ & -29 \\
\hline $\begin{array}{l}\text { Papers where the title, abstract or initial review } \\
\text { indicated that the paper did not deal with crop } \\
\text { simulation of climate change }\end{array}$ & -267 \\
\hline Papers added from IPCC assessment reports & 42 \\
\hline $\begin{array}{l}\text { Papers added from cross-referencing by other } \\
\text { papers }\end{array}$ & 9 \\
\hline Final set of reviewed papers & 221 \\
\hline
\end{tabular}

assessment of use of geospatial analysis (White et al., 2002) and is similar to meta-analyses, which have been used to review results of $\left[\mathrm{CO}_{2}\right]$ enrichment studies (Ainsworth et al., 2002; Kimball et al. 2002).

\section{Materials and methods}

Initially, 628 citations were identified by querying $C A B$ Abstracts (CABI, Oxfordshire, UK) for papers referring to major crops combined with search criteria related to climate change impacts (Table 1). The query included various terms for use of models, climate change, and assessments of impact and adaptation. The initial list was then reduced by including only papers that reported original research on climate change using crop simulation models, that were available through Internet sources, and that were written in English, French, Portuguese or Spanish (languages the reviewers felt competent to review). Thus, papers that described only model development or evaluation, or used models other than dynamic simulations (e.g., regression or econometric) were excluded. The draft set of papers was assessed for completeness by comparison with references cited in the four Assessment Reports of the IPCC (Tegart et al., 1990; Reilly et al., 1996; Gitay et al., 2001; Easterling et al., 2007). The reports cited an additional 42 papers, which were added. Nine more papers were identified through cross-referencing and were included, resulting in a final list of 221 papers dating from 1985 to 2010. Although the sample cannot be considered either comprehensive or free of bias, it appeared to represent adequately the range of methodologies used in climate change scenario studies.

Individual papers were first scored using a written survey, which was revised iteratively as new issues were identified during the review of individual papers (the final version is available as an on-line supplement). The survey questions had a multiple choice format to ensure uniform responses, and unanticipated responses were also recorded. The final 32 sets of survey questions were grouped according to six subject areas. The first category dealt with justification for the selection of the target geographic region(s) and $\operatorname{crop}(\mathrm{s})$. The next concerned what criteria were used for selecting the simulation model(s), the features of a given model, and how that model was evaluated in relation to responses relevant for climate change research. The third category dealt with GHG scenarios and circulation or climate models, and how climate change predictions were converted to the daily weather formats required for simulation, including the temporal and spatial coverage. The fourth category related to adaptation strategies, such as varying planting dates, fertilizer regimes, irrigations (if any), cultivars and crop rotations. The fifth examined which variables were used to assess 
impact and the completeness of the corresponding analyses, which ranged from being completely modeled (e.g., for economic yield) to speculative (e.g., for comments on possible effects of pests and diseases without supporting model outputs). Impact parameters included economic yield, crop phenology and growth, resource use, GHG emissions, and economic return. The final category assessed how risk-related impacts were analyzed, including effects of factors such as water deficits, frost, heat stress, pests, diseases and weeds.

The possibility of tabulating simulated yield responses to climate change was also considered. However, due to the large variation in simulation protocols, in how responses were reported, and in some cases, the diversity of results reported within a single paper, yield responses were not assessed.

To ensure that the survey questions were evaluated in a uniform manner, three papers were evaluated independently by each of three of the authors. The results were compared and where discrepancies were found, the survey questions were revised for clarity or the authors reached a consensus on how to interpret papers in a uniform manner. The data entry process also allowed for extensive cross-checking since all data were entered by the primary author. Nonetheless, we recognize that inconsistencies in interpretation likely occurred when questions required a subjective judgment (e.g., in judging the thoroughness of the rationale provided for selecting a given simulation model). As guidelines, justifications for selection of crops, regions or models were considered to be minimal when only a single sentence was provided, partial for two sentences to a complete paragraph, and thorough if there was more than a paragraph of justification.

Results for each survey were entered into a spreadsheet. The data were then tabulated using the SAS statistical programming language (version 9.2, SAS Institute, Inc., Cary, NC, USA). For questions where variable numbers of responses were possible, such as for names of crops, countries, simulation models, and circulation models, the individual answers for a given paper were weighted as a fraction of the total for that paper. For example, if four crops were considered, each crop was assigned a value of 0.25 . This avoided the potential of over-weighting papers that involved large numbers of countries, crops or simulation models. Questions related to whether models simulated $\mathrm{CO}_{2}$ effects on the crop water balance, heat stress responses (e.g., on grain set), or an energy balance proved difficult to score because descriptions of models often were very brief and understandably, seldom identified features not implemented in the model. Thus, in many cases, papers were scored as "unclear" when the probable situation was that the model in question lacked the specific feature.

Considerable difficulty was also encountered in tabulating the names of crop simulation models, GHG scenarios, GCMs and RCMs. Standard nomenclature for GHG scenarios were only implemented for the IPCC in the Third Assessment Report (TAR; Nakicenovic and Swart, 2000). Names of climate models sometimes combine model versions and GHG scenarios, and many cases model names appeared simply to differ due to inconsistencies in abbreviations or nomenclature.

When additional questions were introduced either through revisions of the survey format or direct entry into the spreadsheet, the complete set of papers was evaluated for each new question. Dates of acceptance for journal papers were obtained from notes in the paper or from the journal web site. Acceptance dates were not found for 28 papers, so they were excluded from analyses requiring the dates.

The review process identified large variation among papers for the assumed baseline $\left[\mathrm{CO}_{2}\right]$ level, so a need was seen to provide an indication of the potential yield impact of these differences. To assess this potential impact, responses of wheat to $380 \mathrm{ppm}$ vs. $330 \mathrm{ppm}\left[\mathrm{CO}_{2}\right]$ were simulated over ten years using the CSMCROPSIM-CERES-Wheat V4.5 (Hoogenboom et al., 2010), assuming soil initial conditions and crop management similar to those for the wheat Free-Air $\mathrm{CO}_{2}$ Enrichment (FACE) experiment conducted at Maricopa, AZ in 1995-1996 (Kimball et al., 1999). The environmental modification routine was used to specify the two $\left[\mathrm{CO}_{2}\right]$ levels, and each simulation was repeated using weather data from 1995 to 2005 .

\section{Results}

\subsection{Representation of crops and geographic regions}

The oldest simulation studies encountered were by Rosenzweig (1985) on wheat and Liverman et al. (1986) on maize. About half of the papers (111) mainly considered impact; an additional 74 papers considered adaptation or methodologies in combination with impact (Table 2). Wheat was the crop most often assessed, followed by maize, rice and soybean (Table 2). Based on FAO data (FAO, 2008), the number of crops assessed showed rough agreement with their importance based on respective areas under cultivation (Fig. 1), although rice and soybean were underrepresented relative to wheat and maize. This may reflect difficulties in accessing rice studies, notably papers from China and India, and underrepresentation of rice and soybean producing countries in climate change research. The geographic coverage was dominated by the USA (55 papers) and European countries (64 papers) (Table 3). Among countries of the former Soviet Union, only three papers dealing with this region were assessed.

Table 2

Numbers of papers classified by stated objectives or procedures used, the crops considered, and how fully the selection of crops was justified.

\begin{tabular}{lr} 
What was the objective or type of paper: & \\
\hline Methodology & 21 \\
Impact & 111 \\
Adaptation & 6 \\
Methodology + Impact & 24 \\
Methodology + Adaptation & 9 \\
Impact + Adaptation & 38 \\
Methodology + Impact + Adaptation & 12
\end{tabular}

Which crops were considered in the papers ${ }^{\mathrm{a}}$ :

\begin{tabular}{|c|c|c|c|}
\hline Alfalfa $^{+b}$ & 1.6 & Pasture grass & 2.3 \\
\hline Bambara & 0.9 & $\mathrm{Pea}^{+}$ & 0.2 \\
\hline Barley $^{+}$ & 3.8 & Peanut $^{+}$ & 4.4 \\
\hline Cabbage $^{+}$ & 0.1 & Phaseolus $^{+}$ & 1.2 \\
\hline Canola, rape and mustard ${ }^{+}$ & 1.9 & Potato $^{+}$ & 7.0 \\
\hline Cassava $^{+}$ & 0.3 & Rice $^{+}$ & 24.5 \\
\hline Cauliflower $^{+}$ & 2.0 & Rye $^{+}$ & 0.1 \\
\hline Chickpea $^{+}$ & 2.3 & Sorghum $^{+}$ & 3.9 \\
\hline Citrus & 0.8 & Soybean $^{+}$ & 15.6 \\
\hline Clover $^{+}$ & 0.2 & Sugar beet ${ }^{+}$ & 4.0 \\
\hline Cotton $^{+}$ & 3.3 & Sugar cane ${ }^{+}$ & 2.1 \\
\hline $\mathrm{Faba}^{+}$ & 1.3 & Sunflower ${ }^{+}$ & 0.7 \\
\hline Kiwi & 0.3 & Switchgrass & 0.4 \\
\hline Maize $^{+}$ & 54.4 & Tobacco & 0.1 \\
\hline Millet $^{+}$ & 0.8 & Tomato $^{+}$ & 0.1 \\
\hline Oats $^{+}$ & 0.5 & Wheat $^{+}$ & 77.1 \\
\hline Onion & 0.1 & Wheatgrass & 0.4 \\
\hline Paspalum sp. & 0.3 & (generic crop & 1.0 \\
\hline
\end{tabular}

How well was the selection of crops justified:

\begin{tabular}{lr}
\hline Thoroughly & 25 \\
Partially & 55 \\
Minimally & 67 \\
No specific crop (generic crop for watershed) & 1 \\
Not at all & 73
\end{tabular}

a Fractions result from weighting when more than one crop was assessed in a single paper.

b A plus sign (" + ") following a crop name indicates that the crop was included in the search of $C A B$ Abstracts used to provide the initial set of papers. 


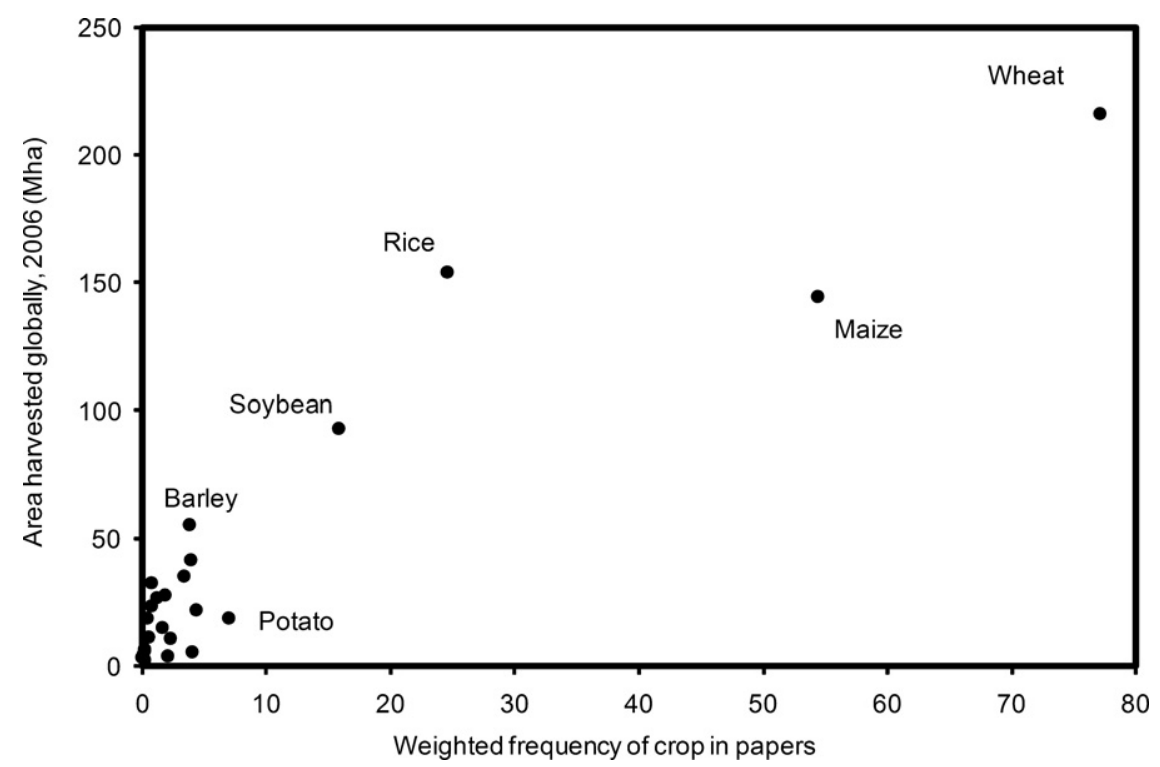

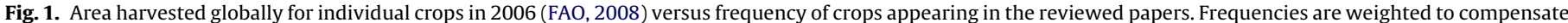
for papers that dealt with more than one crop. Frequencies of individual crops are listed in Table 1.

An associated concern was whether the papers adequately justified the selection of crops, geographic regions and ecophysiological models. About $33 \%$ of the papers did not indicate why the $\operatorname{crop}(\mathrm{s})$ were assessed (Table 2), and $40 \%$ of the papers did not justify the selection of the main geographic region (Fig. 2). Sampling within a region (e.g., selection of specific sites within a country) was partially to fully justified in $29 \%$ of the papers; $33 \%$ covered the entire

Table 3

Number of papers considering specific countries or regions. Fractions resulted from papers where multiple countries or regions were considered.

\begin{tabular}{lrlrlr}
\hline Africa & \multicolumn{3}{c}{ Europe } & North America & \\
Angola & 0.1 & Austria & 4.5 & Canada & 5.3 \\
Botswana & 1.1 & Bulgaria & 2.0 & US & 55.3 \\
Burundi & 0.3 & Czech Rep. & 1.5 & & \\
Cameroon & 3.0 & Denmark & 0.8 & Latin America & \\
Dem. Rep. Congo & 0.2 & Finland & 3.2 & Argentina & 1.0 \\
Ethiopia & 0.1 & France & 3.2 & Brazil & 4.0 \\
Kenya & 0.3 & Germany & 2.0 & Chile & 1.0 \\
Lesotho & 0.5 & Greece & 1.0 & Mexico & 0.3 \\
Malawi & 0.2 & Hungary & 4.2 & Venezuela & 1.0 \\
Mali & 1.0 & Ireland & 3.2 & & \\
Mozambique & 0.2 & Italy & 4.3 & Regions & \\
Nigeria & 1.0 & Netherlands & 0.2 & Africa & 1.5 \\
Rwanda & 0.3 & Portugal & 0.7 & Europe & 7.0 \\
South Africa & 2.0 & Russia & 1.5 & Latin America & 0.5 \\
Swaziland & 1.5 & Romania & 1.0 & Former USSR & 1.0 \\
Tanzania & 0.4 & Slovakia & 1.0 & Global & 4.0 \\
Tunisia & 1.0 & Spain & 5.7 & & \\
Uganda & 0.3 & Switzerland & 2.0 & & \\
Zambia & 0.1 & Ukraine & 0.5 & & \\
Zimbabwe & 2.1 & UK & 14.7 & & \\
Australasia & & Middle East & & & \\
Australia & 13.0 & Iran & 1.5 & & \\
Bangladesh & 1.1 & Egypt & 2.0 & & \\
China & 18.5 & Israel & 2.0 & & \\
India & 17.1 & Syria & 1.5 & & \\
Indonesia & 1.1 & & & & \\
Japan & 2.5 & & & & \\
Malaysia & 0.1 & & & & \\
Myanmar (Burma) & 0.1 & & & & \\
New Zealand & 1.0 & & & & \\
Pakistan & 1.0 & & & & \\
Philippines & 2.5 & & & & \\
South Korea & 0.3 & & & & \\
Taiwan & 0.1 & & & \\
Thailand & 0.5 & & & \\
\hline
\end{tabular}

target region (Fig. 2). Of 164 papers studying impacts at point locations, over half ( 89 papers) considered less than five locations (Fig. 2)

A. Level of justification for selecting region or country.

Thoroughly
Partially
Minimally
Not at all
Global coverage (NA)

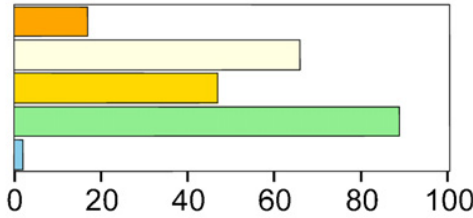

B. Level of justification for sampling within the target region.

Thoroughly

Partially

Minimally

Not at all

Region completely covered

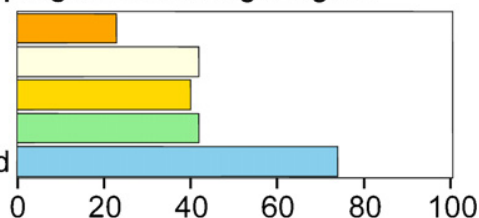

C. How many distinct locations were considered?

Gridded data (NA)

Polygons (NA)

10 or more locations

5 to 10 locations

Less than 5 locations

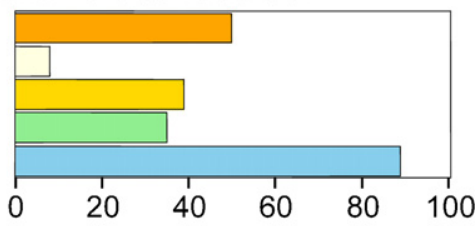

D. How were soil profiles varied over the target region?

Range of profiles

Range of profiles per location

One profile per location

Single profile

No soil or unclear

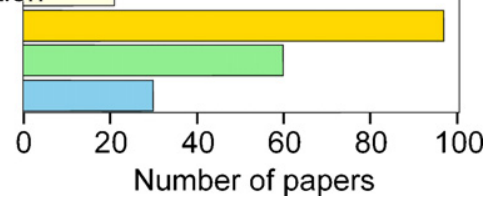

Fig. 2. Numbers of papers classified by various criteria relating to selection of target regions and sampling of locations within regions. (A) Level of justification for selection of the target region. (B) Level of justification for sampling within the target region. (C) The type of spatial data or number of locations considered. (D) How variation in soil conditions was represented. 


\subsection{Ecophysiological models}

\subsubsection{Models used}

Over 70 different simulation models were used (Table 4), but versions of the Crop Environment Resource Synthesis (CERES) and Erosion Productivity Impact Calculator (EPIC) models represented $40 \%$ of the models used ( 88 papers). Both models use RUE to estimate growth on a daily time interval. Eighty-one papers provided at least a partial justification for selection of a given model or cited other papers (Table 4).

\subsubsection{Model evaluation}

Models were evaluated through comparisons with field data from within the study region in 95 papers (43\%) and an additional 73 papers (33\%) cited separate evaluations (Table 4 ). Where evaluations were presented, these often relied on comparisons of means and variances for historic yields, rather than using cross validation. Explicit evaluations of $\mathrm{CO}_{2}$ or temperature responses involving chamber or field studies were presented in only four papers. FACE studies have been used in model development and testing, and merit wider use (Ainsworth et al., 2008). Variation in elevation, latitude and planting dates can be used to test temperature responses, and infrared heating shows promise as a method to increase temperatures $1-3{ }^{\circ} \mathrm{C}$ above ambient in field plots (Kimball et al., 2008), but such approaches were seldom attempted. Controlledenvironment studies also have value if care is taken to allow for possible artifacts due to limited soil volumes and the unnatural aerial environment.

\subsubsection{Modeling approaches and process detail}

Concerns over the level of process detail represented in the ecophysiological models arose from the expectation that a substantial portion of the models would represent the major processes thought to determine plant response to elevated temperatures and $\left[\mathrm{CO}_{2}\right]$. Three modeling approaches predominated in the papers. The simplest approach was to estimate daily net productivity through the products of potential radiation use efficiency (RUE), the integral of photosynthetically active radiation intercepted each day, and various RUE modifiers that, depending on the model, accounted for daily effects of elevated $\left[\mathrm{CO}_{2}\right]$, temperature, water or nutrient deficits and other environmental or physiological factors. The second class of models estimated diurnal variation in leaf-level photosynthesis, which was scaled to canopy level, and considered losses through respiration and senescence. The main effect of elevated $\left[\mathrm{CO}_{2}\right]$ was modeled within the processes of photosynthesis, and water deficits acted through effects on stomatal conductance and tissue growth (e.g., leaf expansion). Temperature potentially affected multiple processes, with tissue and soil temperatures either assumed equal to air temperature or obtained from simple submodels. The third class of models calculated a soil-plant-atmosphere energy balance, typically with sub-hourly time steps. The processes of photosynthesis and respiration were modeled similar to the second class of models. In calculating the components of the energy balance, however, these models estimated foliage temperatures. This allowed modeling the expected increase in canopy temperature associated with reduced stomatal conductance under elevated $\left[\mathrm{CO}_{2}\right]$ (in the absence of more complex interactions such as through changes in plant water and nitrogen status). In FACE experiments, an increase of $\left[\mathrm{CO}_{2}\right]$ of $180 \mathrm{ppm}$ relative to ambient was associated with an average increase in canopy temperature of $0.6^{\circ} \mathrm{C}$ in wheat and $0.8^{\circ} \mathrm{C}$ in cotton (Kimball et al., 2002). Similarly, Cao et al. (2010) estimated that for a doubling of $\left[\mathrm{CO}_{2}\right]$ from 400 to $800 \mathrm{ppm}$, this response would induce a $0.4{ }^{\circ} \mathrm{C}$ warming over land. Thus, failure to consider feedbacks of elevated $\left[\mathrm{CO}_{2}\right]$ on canopy temperature could bias estimated effects of temperature driven responses and most notably, underestimate effects
A. Were effects of $\mathrm{CO}_{2}$ on canopy temperature simulated?

Energy balance No/not applicable Unclear

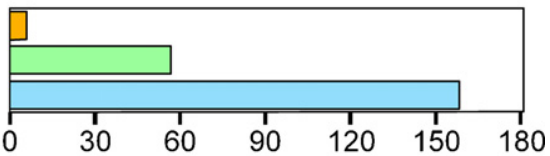

B. Were effects of $\mathrm{CO}_{2}$ on transpiration simulated?

Energy balance Canopy conductance Simple factor No/not applicable Unclear

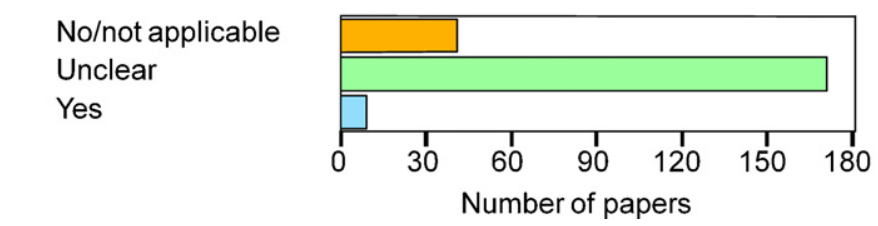

Fig. 3. Number of papers classified based by whether a given ecophysiological model specifically considered effects of: $(\mathrm{A})\left[\mathrm{CO}_{2}\right]$ on canopy temperature. (B) $\left[\mathrm{CO}_{2}\right]$ on transpiration. (C) Elevated temperature on specific processes such as seed set or leaf senescence (heat stress).

of elevated temperatures. However, it should also be noted that GCMs include land surface schemes that model effects of $\left[\mathrm{CO}_{2}\right]$ on canopy conductance which increase the warming above that due to radiative effects of $\left[\mathrm{CO}_{2}\right]$ (Cox et al., 1999).

Only six papers used a crop model that clearly included effects of $\mathrm{CO}_{2}$ on canopy temperature (Fig. 3A). For over 150 papers, the model descriptions were too incomplete to allow a reader to judge whether an energy balance was estimated. However, based on additional knowledge of the models or consideration of the required weather data, it is unlikely that an energy balance was estimated. Similar ambiguity concerned how $\mathrm{CO}_{2}$ effects on transpiration were represented and whether a model explicitly simulated effects of heat stress (Fig. 3B and 3C).

There is widespread debate over the appropriate scale of processes that ecophysiological models should attempt to describe. One position is that due mainly to difficulties in accurate parameterization and in understanding the complexity of the model code, models used as predictive tools should be as simple as possible (Passioura, 1996). A suggested guideline is that models should not encompass more than three levels of scale in a hierarchy of molecular, biochemical, cellular, organ, plant and community processes. The main counter argument is that if models are properly parameterized, tested and documented, there is no logical basis for restricting complexity. Furthermore, the failure of simple models to consider important feedbacks may reduce the accuracy of their predictions. Adam et al. (2011) found that the method of simulating light interception had a surprisingly large effect on yield, which was traced to differences in modeled leaf senescence.

The logical way to understand how process completeness and detail affect model accuracy and usability is through comparisons of models using common datasets, and calls for improved analysis and comparisons of models are hardly original. Both the IPCC assessment reports have cited the need for continued improvement of process-based models (Reilly et al., 1996; Gitay et al., 2001; Easterling et al., 2007), and the fourth assessment report (FAR) further noted that "calls by the third assessment report (TAR) to enhance crop model inter-comparison studies have remained unheeded; in fact, such activity has been performed with much less frequency after the TAR than before." Nonetheless, only eight papers compared models for a common crop, and none assessed 
Table 4

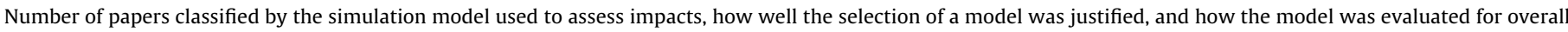
suitability. Fractions resulted from papers where multiple models were used.

\begin{tabular}{|c|c|c|c|c|c|}
\hline AFRCWHEAT & 2.9 & GEPIC & 1.0 & RICESYS & 0.3 \\
\hline APSIM & 13.0 & GLAM & 3.3 & SCRI & 0.3 \\
\hline AWAH & 0.5 & GLYCIM & 2.0 & SIMPOTATO & 0.5 \\
\hline BlastSim & 1.0 & GOSSYM & 3.5 & SIMRIW & 1.5 \\
\hline Broom's barn & 2.0 & HUMUS & 1.5 & SIRIUS & 4.4 \\
\hline CANEGRO & 1.0 & InfoCrop & 3.0 & SOYGRO & 3.3 \\
\hline CENTURY & 3.0 & LINTULCC & 1.0 & STAMINA & 1.0 \\
\hline CERES & 63.2 & LPJ GUESS & 0.3 & STICS & 3.0 \\
\hline CH Farm & 0.3 & LPOTCO & 1.0 & SUBSTOR & 2.0 \\
\hline CMSM & 2.0 & MACROS & 0.3 & SWAT & 0.5 \\
\hline CWHEAT2 & 0.3 & MCWLA & 1.0 & SWIM & 1.0 \\
\hline Climate Soil Yield & 1.0 & MMF erosion & 1.0 & Sinclair & 5.0 \\
\hline CropGro & 6.0 & MUST & 0.7 & SoilN Wheat & 0.4 \\
\hline CropSyst & 9.1 & mVSMB & 1.0 & WATBAL & 0.3 \\
\hline CropWat & 0.3 & Miami & 1.0 & WEATHER YIELD & 1.0 \\
\hline Cyrus & 2.0 & NPOTATO & 0.5 & WECS & 0.7 \\
\hline deWit & 1.0 & Nwheat & 0.4 & WEPP & 6.0 \\
\hline DNDC & 3.0 & ORYZA1 N & 1.0 & WOFOST & 3.0 \\
\hline Daisy & 0.3 & POTATOS & 0.5 & WTGROWS & 1.0 \\
\hline EPIC & 25.2 & PRZM & 0.5 & Wang Engel & 2.0 \\
\hline EuroSunflower & 0.5 & PaSim & 0.3 & YIELD & 1.0 \\
\hline EuroWheat & 1.5 & Phygro & 0.5 & VIP & 1.0 \\
\hline FABEAN & 1.3 & Prarie Ag Bound Layer & 1.0 & Not named (various) & 14.2 \\
\hline
\end{tabular}

How well was the selection of the model(s) justified:

\begin{tabular}{ll}
\hline Thoroughly & 39 \\
Partially & 42 \\
Minimally & 77 \\
Cited other sources & 23 \\
Not at all & 40
\end{tabular}

How were model responses evaluated:

$\begin{array}{ll}\text { Locations within target regions } & 95 \\ \text { Minimal or arbitrary locations } & 4 \\ \text { No evaluations } & 49 \\ \text { Cited other sources } & 73\end{array}$

the impact of an energy balance approach. Suggestions for modularization of code in ecophysiological models (Reynolds and Acock, 1997), which would facilitate testing and interchange of improved components, have largely gone ignored. An encouraging exception is the Agricultural Production and Externalities Simulator (APES) (Donatelli et al., 2009; Adam, 2010).

\subsection{Climate change scenarios}

Over 120 papers used generic scenarios for GHG increase as opposed to formally named scenarios such as IS92A and SRES A1 (Table 5). Scenario naming started with the TAR (Gitay et al., 2001), so earlier studies would not have used named scenarios. Generic scenarios typically involved doubling of $\left[\mathrm{CO}_{2}\right]$ and incremental changes in various combinations of temperature, precipitation or solar radiation.

The most commonly used GCMs were HadCM2 and HadCM3, which together represented about $35 \%$ of GCM usage (Table 5 ). The three most widely used regional climate models were NCAR RCM, PRECIS and UKTR. We note that there was ambiguity in nomenclature for climate models per se, versions and climate simulation experiments. For example, UKCIP is the UK Climate Impacts Programme, and their associated climate datasets have been based on results from HadCM1, HadCM2, and HadCM3 (UKCIP, 2010). Thus, the actual use of the Hadley series of GCMs is likely even greater than Table 5 suggests.

To obtain daily data for future scenarios, 141 papers adjusted historical daily data with outputs of the circulation models or generic effects (Table 6). Sixty-eight papers adjusted parameters of weather generators such as WGEN or LARS-WG to provide artificial sets of daily data intended to be statistically representative of future climates. When multiple locations were considered and circulation or climate model outputs were used, daily weather data usually were adjusted both for geographic and seasonal variation (Table 6).

Climate change impact studies usually specify baseline conditions from which future impacts are projected. The baseline $\left[\mathrm{CO}_{2}\right]$ should correspond to a date roughly contemporaneous with time of the research, perhaps allowing an extra year or two for analysis and writing. In practice, of the 130 papers that described a baseline $\left[\mathrm{CO}_{2}\right]$, over 70 used a value that corresponded to $\left[\mathrm{CO}_{2}\right]$ at least ten years prior to the publication date (Fig. 4), and in 12 papers, the difference was over 30 years. For a paper assuming a $330 \mathrm{ppm}$ baseline which was the concentration in 1975, but published in 2005 when $\left[\mathrm{CO}_{2}\right]$ was approximately $380 \mathrm{ppm}$, the 30 year delay results in a $50 \mathrm{ppm}$ bias. As an example, based on our simulation of spring wheat for Maricopa, AZ using CSM-CROPSIM-CERES, this difference in $\left[\mathrm{CO}_{2}\right]$ corresponds roughly to a $3 \%$ increase in grain yield.

The predominant cause of this bias appears to be that baseline $\left[\mathrm{CO}_{2}\right]$ levels were selected to coincide with the baselines assumed for whichever climate model provided the climate change scenarios. Thus, for a GCM using a baseline of 1960-1990, the $\left[\mathrm{CO}_{2}\right]$ might correspond to $330 \mathrm{ppm}$, the approximate level in 1975 , or $354 \mathrm{ppm}$ for 1990 . The underlying issue is that the baseline periods associated with climate projections were substantially earlier (1960-1990) than seems desirable (Fig. 5A). Ideally, the baseline time period should be long enough to ensure a reliable estimate and should terminate as close to the publication date as possible. For the 164 papers that specified the baseline period, the aver- 
Table 5

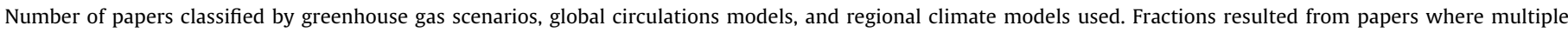
scenarios or models were considered.

\begin{tabular}{|c|c|c|c|c|c|}
\hline \multicolumn{6}{|c|}{ Number of papers which used a given greenhouse gas scenario } \\
\hline Generic doubling of $\left[\mathrm{CO}_{2}\right]$ & 81.7 & IS92F & 0.2 & A2 & 20.9 \\
\hline Generic other scenarios & 39.5 & IS95A & 3.0 & B1 & 4.9 \\
\hline GGa1 & 2.9 & A1 & 1.8 & B2 & 13.2 \\
\hline IS92A & 23.1 & A1B & 2.2 & Ensemble & 1.0 \\
\hline IS92 C & 0.3 & A1FI & 7.7 & Not specified & 13.0 \\
\hline IS92E & 1.5 & $\mathrm{~A} 1 \mathrm{~T}$ & 0.2 & & \\
\hline \multicolumn{6}{|c|}{ Number of papers which used a given global circulation model } \\
\hline Generic & 66.5 & CSM 1 & 0.0 & HadCM2 & 18.7 \\
\hline Ensemble & 2.5 & CSM 13 & 0.0 & HadCM3 & 34.5 \\
\hline GCM unclear & 3.0 & ECHAM & 0.2 & HCGG & 0.1 \\
\hline AOGCM & 0.0 & ECHAM3 LSG & 0.6 & HCGS & 0.1 \\
\hline ARPEGE & 0.6 & ECHAM4 OPYC3 & 3.2 & LMD & 1.0 \\
\hline ARPEGE OPA1 & 1.1 & ECHAM4 OPYC4 & 0.8 & MAGICC & 1.0 \\
\hline ARPEGE OPA2 & 0.3 & ECHAM T21 & 0.5 & MK2 CSIRO & 9.4 \\
\hline ARPEGE CLIMAT & 0.5 & GFDL & 12.2 & MK3 CSIRO & 0.0 \\
\hline BMRC & 1.6 & GFDL-R15 & 0.5 & MPI & 0.7 \\
\hline BMRCa & 0.0 & GFDL-R15 a & 0.3 & NCAR CCM3 & 1.0 \\
\hline $\mathrm{BMRCb}$ & 0.0 & GFDL-R15 b & 0.0 & OSU & 0.9 \\
\hline C-CAM & 1.0 & GFDL-R30 c & 0.6 & PCM DOE NCAR & 2.5 \\
\hline $\mathrm{CCC}$ & 1.4 & GISS & 11.3 & UIUC & 0.0 \\
\hline cCCma & 5.0 & GISS1 & 1.5 & UKLO & 0.5 \\
\hline CCSR NIES & 0.0 & GISS2 & 0.6 & UKMO & 6.6 \\
\hline CGCM1 & 4.5 & GISS6 & 0.5 & UKTR & 2.1 \\
\hline CGCM2 & 1.7 & GISSTR & 0.3 & UK89 & 0.1 \\
\hline CSIRO GCM & 2.5 & HadAM3H & 4.5 & & \\
\hline \multicolumn{6}{|c|}{ Number of papers which used a given regional climate model } \\
\hline None or not specified & 171.0 & HadRM3P & 1.1 & RACMO & 0.5 \\
\hline ARPEGE regional & 1.2 & HIRHAM & 1.5 & RCAO & 0.4 \\
\hline CHRM & 0.2 & KNMI & 0.1 & RegCM NCAR & 13.2 \\
\hline CLM & 0.2 & Oz Clim & 2.0 & REMO & 1.1 \\
\hline DARLAM & 1.0 & PNNL RCM & 1.0 & UKCIP & 2.0 \\
\hline EDM & 0.0 & PRECIS & 8.0 & UKH1 & 2.0 \\
\hline HadRM3H & 4.2 & PROMES & 1.2 & & \\
\hline
\end{tabular}

age duration was 32 years. The period from 1960 or 1961 to 1989 , 1990 or 1991 was used in 52 papers and appeared to correspond to a period used in major collaborative projects (e.g., PRUDENCE as described by Christensen et al., 2007). Considering papers that used generic climate scenarios and thus should not have been constrained for baseline periods, of 45 papers that reported baseline $\left[\mathrm{CO}_{2}\right]$ and the respective acceptance dates, 26 papers used baseline
$\left[\mathrm{CO}_{2}\right]$ that corresponded to levels from 10 years or earlier than the acceptance date. Thus, even when there was no constraint due to climate models, the bias in baseline $\left[\mathrm{CO}_{2}\right]$ was found.

The ranges of $\left[\mathrm{CO}_{2}\right]$ considered in future scenarios also varied greatly. "Doubling" of $\left[\mathrm{CO}_{2}\right]$ was variously described as doubling from a pre-industrial value of approximately $280 \mathrm{ppm}$, giving a value around $560 \mathrm{ppm}$, the doubling of recent values ranging from

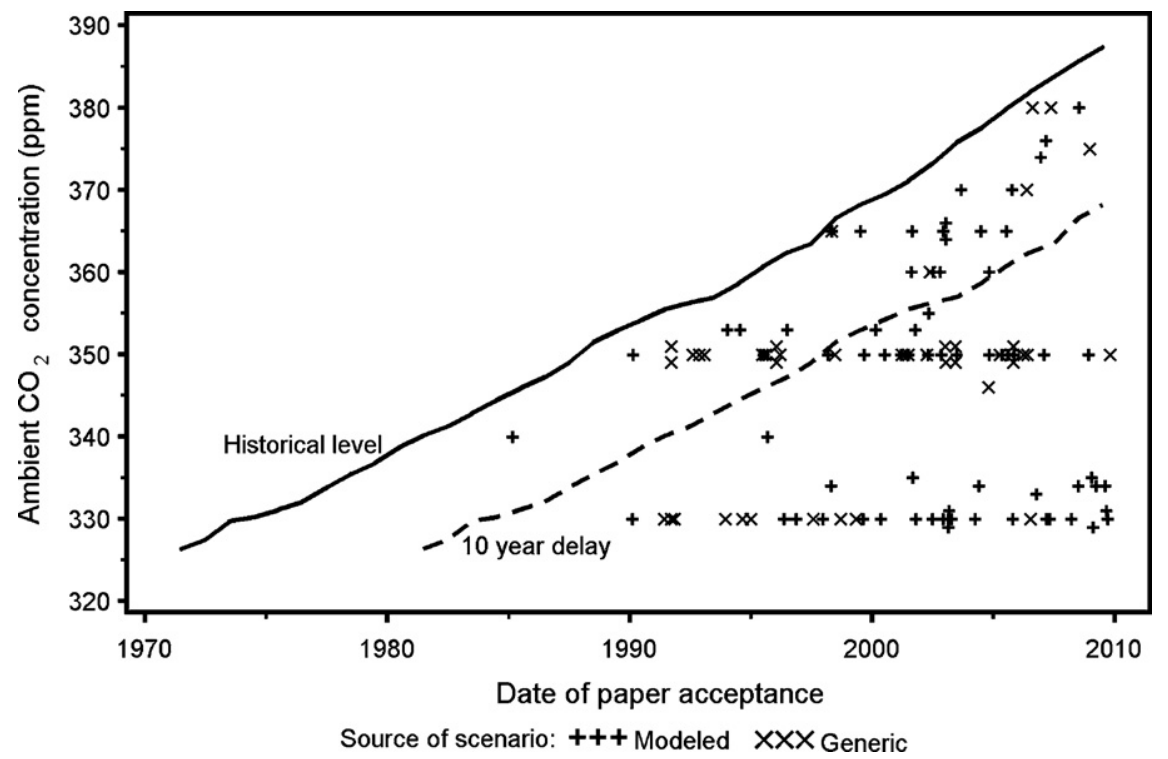

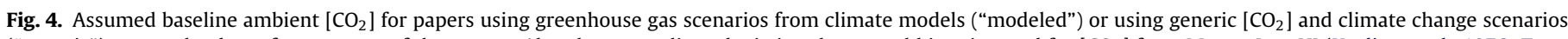

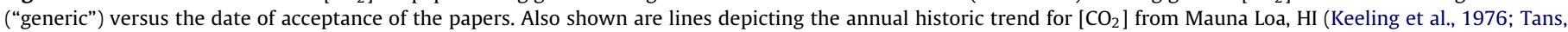
2010) and for a 10-year lag of the same trend. 
Table 6

Number of papers classified by how global circulation model (GCM) or regional climate model (RCM) outputs were downscaled, which weather variables or atmospheric gasses were modified, how weather data were modified, weather generators used (if any), whether scenarios were implemented as continuous change or for discrete time steps, and whether simulations were run continuously or were reinitialized each season.

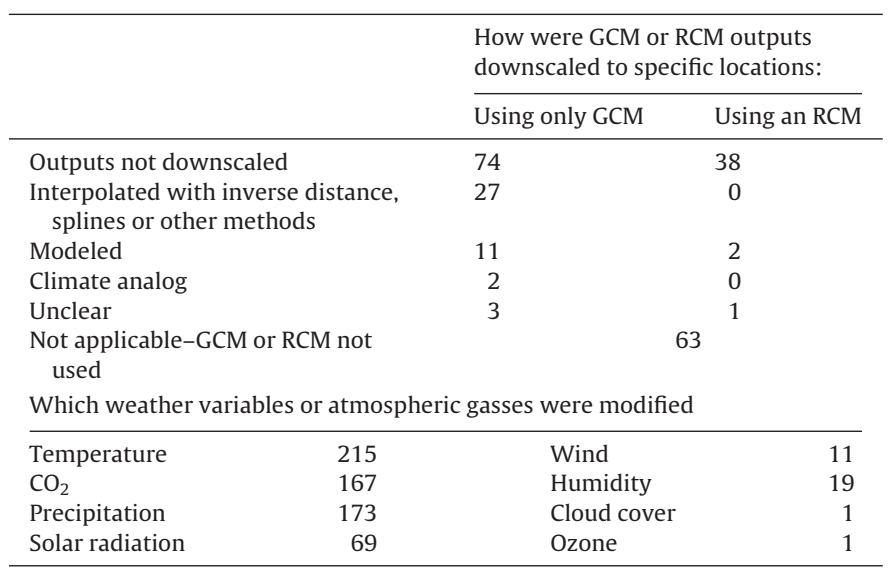

How were modifications to weather variables introduced:

\begin{tabular}{lr}
\hline Adjustment to historic data & 141 \\
GCM or RCM used directly & 6 \\
Weather generator & 68 \\
Climate analog & 3 \\
Not applicable & 3
\end{tabular}

Number of papers using a given weather generator:

\begin{tabular}{lrllll}
\hline Century & 1 & MarkSim & 4 & WGEN & 5 \\
Chinese Weather Generator & 2 & Met \& Roll & 2 & WGEN + WMAK & 2 \\
ClimGen & 5 & MODAWEC & 1 & WPAR & 1 \\
CLIGEN & 6 & SAMS & 1 & WXGEN & 1 \\
EPIC & 7 & SIMMETEO & 3 & Unnamed & 6 \\
LARS-WG & 20 & Sirotenko \& Pavlova & 1 & &
\end{tabular}

How were effects of climate change varied over the season or year and locations or region:

Constant over time and locations

Varied over time but constant over locations

Constant over time but varied over locations

Varied over time and locations

Unclear

Were modifications to weather variables and atmospheric composition changed continuously with time or changed with discrete steps (typically at 20 to 50 year intervals):

\begin{tabular}{lr}
\hline Continuous & 7 \\
Stepped & 214
\end{tabular}

Were simulations run continuously over entire study period, thus allowing for carryover or were they re-initialized for each cropping season:

\begin{tabular}{lr}
\hline Continuous & 12 \\
Re-initialized each cropping season & 209 \\
\hline
\end{tabular}

300 to $374 \mathrm{ppm}$, or doubling of GHG equivalents. For studies using formal scenarios applied to GCMs, there was large variability (Fig. 5B), reflecting both variation in the IPCC scenarios for GHG and the target dates. The foremost consequence of the variability in future $\left[\mathrm{CO}_{2}\right]$ scenarios is that comparisons across studies require that results either be filtered or interpolated to represent standardized $\left[\mathrm{CO}_{2}\right]$ levels.

Fifty-four papers ignored effects of $\left[\mathrm{CO}_{2}\right]$ (Table 6 ). These tended to be papers published prior to 2000 . Over $73 \%$ of the papers (162) simultaneously varied temperature, $\left[\mathrm{CO}_{2}\right]$ and precipitation. Sixtynine papers varied solar radiation, 11 varied wind speed, and 19 varied relative humidity. Only one paper simulated response to atmospheric ozone.

Projections from most climate models are referenced to specific periods rather than presenting transitional data over many decades. This reflects in part difficulties found in conducting the requisite transient climate experiments (Viner et al., 1995). Nonetheless, seven experiments modified climate and weather data continuously (Table 6 ). Similarly, only 12 papers ran models continuously over years, as opposed to reinitializing the simulations each cropping season (Table 6).

\subsection{Adaptation strategies}

Simulation models can readily test crop management options (Tsuji et al., 1998) and thus examine potential for technological adaptations to climate change. Such options include improved varieties, shifts in recommended planting dates and rates, novel cropping sequences, change in the number of fallow years required for soil-water recharge in rainfed systems, and introduction of alternative or new crops. One-hundred and sixty-six papers considered adaptation, and 73 studies varied at least two management practices (Table 7). Planting date was the most frequently varied option. To select a near-optimal planting date under variable and changing climates, 31 papers used software routines that evaluated soil temperature or moisture on a daily basis to determine when conditions would allow sowing. Just nine papers considered tillage practices, and eleven compared crop rotations.

Thorough testing of adaptation options appeared to be constrained by multiple forces. To appreciate these difficulties, one only has to consider the rapid, recent adoption of glyphosate resistant cultivars and zero-tillage (Marshall, 1999; Lobb et al., 2007) or recent interest in novel crops as sources of bioenergy feedstocks (Yuan et al., 2008). The foremost problem is in prioritizing among potentially adaptive changes in management, especially for interacting practices such as planting dates and irrigation management. Cultivar traits are also problematic. Prospects for improving adaptation to elevated $\left[\mathrm{CO}_{2}\right]$, heat stress, drought and water deficits, and nutrient use efficiency are highly uncertain and many improvements would likely interact with crop management.

The "smart farmer' scenario" paper by Easterling et al. (1992) is notable as an early example of thorough examination of adaptation options, including planting dates, nitrogen levels, and the possibility of introducing a fallow. This work also stands out for early use of expert opinion to select the potential adaptations. Nonetheless, the authors reported that they were constrained by the inability of the model (EPIC) to simulate farmer suggestions such as planting genetic mixtures and reduced tillage of row crops. The scarcity of well-tested models that deal with tillage likely explains why few studies considered tillage practices.

\subsection{Impacts assessed}

Impacts of climate change were predominantly evaluated for economic yield (Table 8). Exceptions mainly involved papers that focused on crop distribution or natural resource issues, including soil erosion and carbon storage. Crop models can describe a large number of processes and output a large number of rate and state variables besides economic yield. Thus, 131 papers examined impacts besides yield, with one paper considering 13 of the impact variables that we tabulated (Van Ittersum et al., 2003). Just five papers examined impacts on soil carbon levels and six on GHG emissions (Table 8). This again may relate to the lack of crop models that were considered suitable for simulating effects of tillage and residue management.

For annual crops, given that crop duration typically is reduced and closely associated with yield reduction, one might 

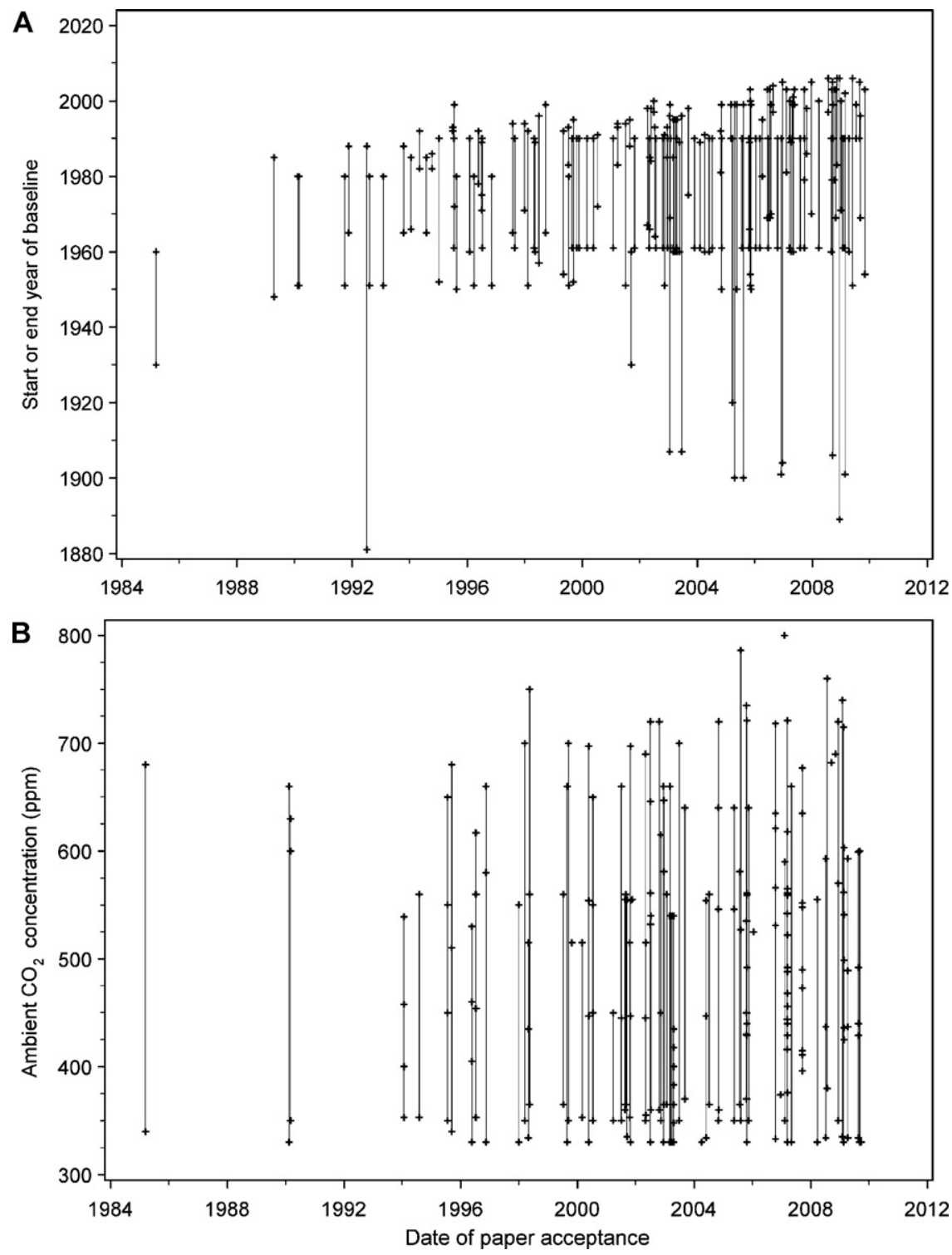

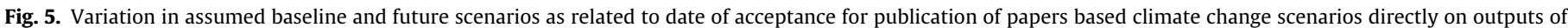
climate models. The lines link multiple values from a single paper. (A) Onset and duration of baseline weather periods. (B) Assumed baseline and future ambient [ $\left.\mathrm{CO}_{2}\right]$.

expect that papers that assessed impacts on yield would examine whether changes in economic yield were primarily due to changes in phenology. Of the 175 papers judged to fully assess economic yield, only 51 fully analyzed impacts on phenology.

\subsection{Assessment of risk}

A widespread concern with climate change is whether the frequency of extreme adverse events such as droughts, heat waves or hurricanes will increase, further threatening the stability of

Table 7

Number of papers that tested specific cropping practices as a potential for adaptation and the total number of practices that were varied per paper.

\begin{tabular}{|c|c|c|c|c|c|c|}
\hline Practice & No adaptation & $2-4$ options & 5 or more options & & Automatic regime & Not applicable \\
\hline Planting date & 119 & 34 & 37 & & 31 & 0 \\
\hline Fertilization & 186 & 17 & 10 & & 8 & 0 \\
\hline Tillage practices & 197 & 10 & 1 & & 0 & 13 \\
\hline Irrigation & 23 & 28 & 3 & & 19 & 148 \\
\hline Cultivar & 157 & 32 & 14 & & $18^{\mathrm{b}}$ & 0 \\
\hline \multirow[t]{2}{*}{ Cropping system ${ }^{c}$} & 209 & 9 & 3 & & 0 & 0 \\
\hline & \multicolumn{2}{|r|}{ None } & 1 & 2 & 3 & $>3$ \\
\hline \multicolumn{2}{|c|}{ Total practices varied per paper } & 55 & 73 & 59 & 26 & 8 \\
\hline
\end{tabular}

a Includes rainfed conditions.

b Varied cultivar traits rather than individual cultivars.

c Typically involved comparison of crop rotations. 
Table 8

Number of papers that assessed climate change impact for a given crop, environmental or socio-economic variable.

\begin{tabular}{|c|c|c|c|c|c|}
\hline \multirow[t]{2}{*}{ Assessment of impact in terms of: } & \multicolumn{5}{|c|}{ Completeness of assessment } \\
\hline & Full & Partial & Semi-quantitative & Qualitative & Speculative \\
\hline Economic yield & 175 & 11 & 1 & 3 & 0 \\
\hline Biomass & 32 & 6 & 0 & 2 & 0 \\
\hline Yield quality (e.g., grain nitrogen conc.) & 9 & 4 & 0 & 3 & 0 \\
\hline Yield components (e.g., mass/grain) & 11 & 0 & 0 & 2 & 0 \\
\hline Phenology (flowering, maturity) & 62 & 12 & 1 & 6 & 0 \\
\hline Harvest date & 17 & 2 & 2 & 1 & 0 \\
\hline Water use or evapotranspiration & 45 & 6 & 6 & 4 & 0 \\
\hline Water use efficiency & 22 & 1 & 0 & 1 & 0 \\
\hline Water stress index (of simulation model) & 6 & 0 & 0 & 0 & 0 \\
\hline Soil water level or groundwater recharge & 18 & 2 & 0 & 1 & 0 \\
\hline Runoff & 13 & 1 & 1 & 0 & 0 \\
\hline Nitrogen use or uptake & 7 & 2 & 0 & 0 & 0 \\
\hline Nitrogen use efficiency & 0 & 0 & 0 & 0 & 0 \\
\hline Soil nitrogen level & 4 & 1 & 0 & 0 & 0 \\
\hline Soil carbon & 4 & 1 & 0 & 0 & 0 \\
\hline Greenhouse gas emissions & 5 & 1 & 0 & 0 & 0 \\
\hline Soil erosion & 13 & 0 & 0 & 0 & 0 \\
\hline Salinity & 2 & 0 & 0 & 0 & 1 \\
\hline Geographic distribution of crop & 10 & 8 & 4 & 4 & 1 \\
\hline Net economic return & 11 & 2 & 1 & 1 & 0 \\
\hline Regional or global markets & 2 & 1 & 0 & 0 & 0 \\
\hline Other impacts ${ }^{\mathrm{a}}$ & 40 & 5 & 1 & 0 & 1 \\
\hline
\end{tabular}

a Included: Aridity, Bowen ratio, Climate class, Economic indicators, Fractional leaf area, Harvest index, Irrigation use efficiency, Land area suitable for bench terracing,

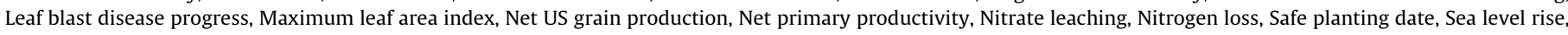
Surface pesticide loss, Water stress index, Water stress, Water temperature, Water yield (watershed scale), Water yield, Yield loss.

agricultural production (Easterling et al., 2007; Allan and Soden, 2008). While 119 papers considered variability or risk, the analyses often involved little more than comparing coefficients of variation. Cumulative probability distributions are more informative and deserve wider use (Thornton and Hoogenboom, 1994; Thornton and Wilkens, 1998).

Among specific components of risk (Table 9), variability due to drought was considered the most often (62 papers). Given the potential importance of heat stress, surprisingly few papers (14) partially or fully considered heat stress. For biotic factors affecting variability, no papers provided quantitative analyses of effects of pests, but two papers modeled effects of rice blast (Pyricularia grisea Cav.; Luo et al., 1998a,b), and one paper partially examined effects of red rice as a weed in cultivated rice (Lago et al., 2008).

\subsection{General discussion}

The evaluations of the paper revealed numerous issues relating to protocols for modeling impacts of climate change on crop production. Issues noted regarding access to papers may have slightly biased the results, but the overall trends seem likely to hold and of course are directly relevant to the 221 papers that were reviewed. Another concern is the potential for bias in evaluating the more subjective criteria such as thoroughness of justifications, but again, the main trends were large enough that the conclusions should be robust.

Based on the criteria used in our assessment, no single paper would be judged as "complete." A "complete" paper would fully justify the selection of crops, locations, and models, document and evaluate key responses of the crop models including sources of uncertainty, apply the GHG scenarios with a robust methodology for down-scaling, use clearly described crop initial conditions that reflect regional variation in soils and cropping practices, consider various options for adaptation selected in part through consultation with producers, and analyze the results both in terms of mean impacts and variability or risk. A few large studies were presented as a set of papers, usually with an introductory paper (or papers) to describe the region, the climate change scenarios and the simulation model(s). Two examples are the series of papers on impacts over the MINK region (Rosenberg et al., 1993) and for the continental US (Rosenberg et al., 2003). Additional detailed accountings have been published as books or reports (e.g., Rosenzweig et al., 1995; Stokes and Howden, 2008).

Regardless of whether results are presented as a single paper or a series, authors should ensure that their publications facilitate interpretation and can allow readers to reproduce the simulations

Table 9

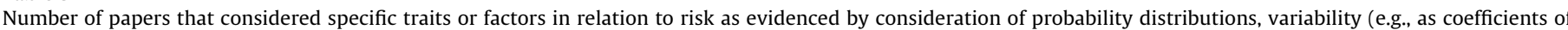
variation) or frequencies over time.

\begin{tabular}{|c|c|c|c|c|c|}
\hline \multirow[t]{2}{*}{ Considers risk in terms of: } & \multicolumn{5}{|c|}{ Completeness of assessment } \\
\hline & Full & Partial & Semi-quantitative & Qualitative & Speculation \\
\hline Production per se & 49 & 11 & 0 & 1 & 0 \\
\hline Heat stress & 4 & 10 & 0 & 4 & 2 \\
\hline Frost or winter-kill & 1 & 1 & 2 & 5 & 1 \\
\hline Drought or water deficit & 12 & 20 & 9 & 18 & 3 \\
\hline Severe storm events & 0 & 0 & 1 & 2 & 3 \\
\hline Insects or nematodes & 0 & 0 & 0 & 2 & 4 \\
\hline Disease & 2 & 0 & 0 & 2 & 6 \\
\hline Weeds & 0 & 1 & 0 & 2 & 2 \\
\hline Other risk factors ${ }^{\mathrm{a}}$ & 5 & 3 & 6 & 0 & 0 \\
\hline
\end{tabular}

\footnotetext{
a Included: Nitrogen stress, Nutrient stress, Phenology, Phosphorus stress, Temperature stress, Water stress.
} 
Table 10

Recommended procedures to improve assessments of climate change in agroecosystems.

- Justify the selection of the simulation model(s) and describe the model(s) with sufficient detail to allow a reader to understand how key processes are represented. Specifically, describe whether transpiration is affected by $\left[\mathrm{CO}_{2}\right]$, whether canopy temperature is estimated, and whether specific heat stress effects (e.g., reducing pollen fertility, increasing embryo or grain abortion or accelerating leaf senescence) are modeled.

- Clearly specify the assumed baseline $\left[\mathrm{CO}_{2}\right]$ and corresponding time period, ensuring that baselines assumed for the simulations and for climate data are consistent with each other.

- Ensure that the end date of the baseline climate data is as close to the date of paper submission as possible.

- When appropriate, use current IPCC greenhouse gas scenarios and identify these with the recognized abbreviations in addition to a text description.

- State which weather variables are modified and if applicable, how outputs from GCMs and/or RCMs are downscaled.

- Assess impacts of soil variability, which might include season to season differences in initial conditions and local spatial variation.

- Ensure that adaptation strategies represent as likely a set of alternatives as possible, preferably by consulting with producers and other stakeholders familiar with the target production environments.

- Examine impacts beyond economic yield, especially as related to soil and water resources.

- Assess impacts in terms of risk, preferably using probability distributions rather than simple statistics such as coefficients of variation.

- To provide a balanced assessment of climatic risk in relation to other source of variation, simulate effects of other sources of variability such as sowing dates and seed rates.

and analyses. The selection of crops and regions should be justified based on criteria such as economic importance or representation of specific issues. Crop models should demonstrably be suitable for their proposed application, and key responses such as those for effects of $\left[\mathrm{CO}_{2}\right]$ on transpiration and for heat stress on grain set or leaf senescence should be described. Although not examined in detail in this review, demonstrating suitability should include a thorough, well-structured evaluation process, as advocated by Alexandrov et al.(2011). Explanations of the climate change scenarios considered should include the baseline time period and $\left[\mathrm{CO}_{2}\right]$, the scenario per se (preferably identified with an IPCC-type name), the weather variables modified, how outputs of any GCM or RCM were downscaled, and similar details (Table 10).

The topics examined variously argue for under and overestimation of predicted mean impacts, over-estimation of impacts on risk, and under-estimation of potential for adaptation. The analyses do not suggest deliberate bias motivated by personal or political interests. Rather, the difficulties are inherent in predicting the behavior of complex systems where there is large uncertainty over underlying processes and values of initial conditions.

Projections of impact and risk need to be interpreted in the context of the difficulties inherent in using a deterministic model to simulate the highly stochastic processes of agroecosystems. Most papers only considered variation in weather conditions as the source of stochastic variation, yet values of model input variables or parameters are estimates, often with uncertainty that is stochastic due to variation in farmer behavior, machinery performance, spatial variability of individual fields, effects of diseases, pests or weeds, and numerous other factors. To accurately simulate expected variability, a modeling study should assess the potential impact of the major factors that have a large stochastic component. Thus, rather than assume a fixed or automatically determined planting date and a constant seed rate, a study might sample a range of dates and seed rates, mimicking these intrinsically variable aspects of crop management. Soil profile descriptions are another source of uncertainty in simulations. The profiles typically provide information on initial water, nutrient levels and organic matter concentrations as well as soil properties that are less dynamic, including drainage and runoff characteristics, bulk density, water holding capacity, and maximum depth for root development. However, the values for these properties have large uncertainties due both to within field variability and to measurement error. Nonetheless, only 21 papers tested more than one soil profile description for a single location, map polygon or grid cell (Fig. 2D), and of these, only ten papers quantified effects on variability, considering only productivity and drought-related risk. The net result is that impacts of climate change on risk likely were overestimated relative to factors ranging from variability in initial plant populations to sub-optimal weed and water management due to labor constraints.

\section{Conclusions}

Diverse methods, scenarios, and models have been used to characterize the potential impacts of climate change on crop yield and other associated aspects of agricultural production. This is a predictable result of the uncertainties over projected changes in $\left[\mathrm{CO}_{2}\right]$ and climate and of a "learning phase" where researchers were testing different methodologies. However, this diversity weakens the comparisons and syntheses that stakeholders require and likely has introduced unintended biases.

No single change in protocols is likely to result in a major improvement in accuracy and comparability of impact studies. Rather, numerous small adjustments in protocols and reporting are needed (Table 10). The single action that might most benefit research on potential impacts of climate change is to establish a coordinated resource for crop management, climate, and soil data, building on resources such as the North American Regional Climate Change Assessment Program (Mearns et al., 2009) and the ICASA Data Exchange (Bostick et al., 2004). A second action would be for model developers to strive for greater modularity with the goal of facilitating model testing and improvement. A third step would be to examine in a more comprehensive fashion how best to simulate the stochastic nature of agroecosystems using deterministic ecophysiological models. All three of these steps implicitly argue for impact studies to involve strong interdisciplinary collaborations.

\section{Acknowledgments}

We thank Charles Wortmann and Jawoo Koo for valuable comments. Conducted under USDA ARS Climate Change, Soils, and Emissions. The USDA is an equal opportunity provider and employer.

\section{Appendix A. Supplementary data}

Supplementary data associated with this article can be found, in the online version, at doi:10.1016/j.fcr.2011.07.001.

\section{References}

Adam, M.Y.O., 2010. A framework to introduce flexibility in crop modelling: from conceptual modelling to software engineering and back. PhD thesis. Plant Production Systems. Wageningen University, Wageningen, pp. 190.

Adam, M., Van Bussel, L.G.J., Leffelaar, P.A., Van Keulen, H., Ewert, F., 2011. Effects of modelling detail on simulated potential crop yields under a wide range of climatic conditions. Ecol. Model. 222, 131-143.

Ainsworth, E.A., Davey, P.A., Bernacchi, C.J., Dermody, O.C., Heaton, E.A., Moore, D. Morgan, P.B., Naidu, S.L., Ra, H.S.Y., Zhu, X.G., Long, S.P., 2002. A meta-analysis of elevated [CO2] effects on soybean (Glycine max) physiology, growth and yield. Global Change Biol. 8, 695-709.

Ainsworth, E.A., Beier, C., Calfapietra, C., Ceulemans, R., Durand-Tardif, M., Farquhar, G.D., Godbold, D.L., Hendrey, G.R., Hickler, T., Kaduk, J., Karnosky, D.F., Kimball, B.A., Korner, C., Koornneef, M., Lafarge, T., Leakey, A.D.B., Lewin, K.F., Long, S.P., Manderscheid, R., McNeil, D.L., Mies, T.A., Miglietta, F., Morgan, J.A., Nagy, J., Norby, R.J., Norton, R.M., Percy, K.E., Rogers, A., Soussana, J.-F., Stitt, M., Weigel, H.-J., White, J.W., 2008. Next generation of elevated $\left[\mathrm{CO}_{2}\right]$ experiments with crops: A critical investment for feeding the future world. Plant Cell Environ. 31, 1317-1324. 
Alexandrov, G.A., Ames, D., Bellocchi, G., Bruen, M., Crout, N., Erechtchoukova, M., Hildebrandt, A., Hoffman, F., Jackisch, C., Khaiter, P., Mannina, G., Matsunaga, T., Purucker, S.T., Rivington, M., Samaniego, L., 2011. Technical assessment and evaluation of environmental models and software: Letter to the. Environ. Model. Software 26, 328-336.

Allan, R.P., Soden, B.J., 2008. Atmospheric warming and the amplification of precipitation extremes. Science 321, 1481-1484.

Bostick, W.M., Koo, J., Walen, V.K., Jones, J.W., Hoogenboom, G., 2004. A web-based data exchange system for crop model applications. Agron. J. 96, 853-856.

Cao, L., Bala, G., Caldeira, K., Nemani, R., Ban-Weiss, G., 2010. Importance of carbon dioxide physiological forcing to future climate change. Proc. Nat. Acad. Sci. 107. 9513-9518.

Challinor, A.J., Ewert, F., Arnold, S., Simelton, E., Fraser, E., 2009. Crops and climate change: Progress, trends, and challenges in simulating impacts and informing adaptation. J. Exp. Bot. 60, 2775-2789.

Christensen, J., Carter, T., Rummukainen, M., Amanatidis, G., 2007. Evaluating the performance and utility of regional climate models: the Prudence Project. Clim. Change 81, 1-6.

Cox, P.M., Betts, R.A., Bunton, C.B., Essery, R.L.H., Rowntree, P.R., Smith, J., 1999. The impact of new land surface physics on the GCM simulation of climate and climate sensitivity. Clim. Dynam. 15, 183-203.

Donatelli, M., Russell, G., Rizzoli, A., 2009. APES: The Agricultural Production and Externalities Simulator. In: Van Ittersum, M.K., Wolf, J., van Laar, H.H. (Eds.), AgSAP conference 2009. Wageningen University and Research Centre, The Netherlands, Egmond aan Zee, The Netherlands, pp. 206-207.

Easterling, W.E., Rosenberg, N.J., Lemon, K.M., McKenney, M.S., 1992. Simulations of crop responses to climate change: effects with present technology and currently available adjustments (the 'smart farmer' scenario). Agric. Forest. Meteorol. 59, 75-102.

Easterling W.E., Aggarwal P.K., Batima P., Brander K.M., Erda L., Howden S.M., Kirilenko A., Morton J., Soussana J.-F., Schmidhuber J., Tubiello F.N., 2007. Food, fibre and forest products. In: Parry, M.L., Canziani, O.F., Palutikof, J.P., van der Linden, P.J., Hanson, C.E. (Eds.), Climate Change 2007: Impacts, Adaptation and Vulnerability. Contribution of Working Group II to the Fourth Assessment Report of the Intergovernmental Panel on Climate Change. Cambridge University Press, Cambridge, UK. pp. 273-313.

FAO., 2008. FAOSTAT. faostat.fao.org (verified 28 June 2011).

Hoogenboom, G., Jones, J.W., Wilkens, P.W., Porter, C.H., Batchelor, W.D., Hunt, L.A., Boote, K.J., Singh, U., Uryasev, O., Bowen, W.T., Gijsman, A.J., du Toit, A., White, J.W., Tsuji, G., 2010. Decision Support System for Agrotechnology Transfer (DSSAT) Version 4. University of Hawaii, Honolulu, Hawaii (CD-ROM).

Gitay, H., Brown, S., Easterling, W. Jallow, B., 2001. Ecosystems and their goods and services. In: McCarthy, J.J., Canziani, O.F., Leary, N.A., Dokken, D.J., White, K.S. (Eds.), Climate Change 2001: Impacts, Adaptation, and Vulnerability. Third Assessment Report of the Intergovernmental Panel on Climate Change. Cambridge University Press, Cambridge, UK, pp. 235-342.

Iglesias, A., Erda, L., Rosenzweig, C., 1996. Climate change in Asia: a review of the vulnerability and adaptation of crop production. Water Air Soil Pollut. 92, 13-27.

Katz, R.W., 1977. Assessing the impact of climatic change on food production. Clim. Change 1, 85-96.

Keeling, C.D., Bacastow, R.B., Bainbridge, R.B., Ekdahl Jr., C.A., Guenther, P.R., Waterman, L.S., Chin, J.F.S., 1976. Atmospheric carbon dioxide variations at Mauna Loa Observatory, Hawaii. Tellus 28, 538-551.

Kimball, B.A., Conley, M.M., Wang, S., Xingwu, L., Morgan, J.A., Smith, D.P., 2008. Infrared heater arrays for warming ecosystem field plots. Global Change Biol. $14,309-320$.

Kimball, B.A., Kobayashi, K., Bindi, M., 2002. Responses of agricultural crops to freeair $\mathrm{CO}_{2}$ enrichment. Adv. Agron. 77, 293-368.

Kimball, B.A., LaMorte, R.L., Pinter Jr., P.J., Wall, G.W., Hunsaker, D.J., Adamsen, F.J., Leavitt, S.W., Thompson, T.L., Matthias, A.D., Brooks, T.J., 1999. Free-air CO2 enrichment (FACE) and soil nitrogen effects on energy balance and evapotranspiration of wheat. Water Resour. Res. 35, 1179-1190.

Liverman, D.M., Terjung, W.H., Hayes, J.T., Mearns, L.O., 1986. Climatic change and grain corn yields in the North American Great Plains. Clim. Change 9, 327347.

Lobb, D.A.R., Huffman, E., Reicosky, D.C., 2007. Importance of information on tillage practices in the modelling of environmental processes and in the use of environmental indicators. J. Environ. Manag. 82, 377-387.

Lago, I., Streck, N.A., Alberto, C.M., Oliveira, F.B., Paula, G.M.de., 2008. Impact of increasing mean air temperature on the development of rice and red rice. Pesqui. Agropecu. Bras. 43, 1441-1448.

Luo, Y., Teng, P.S., Fabellar, N.G., TeBeest, D.O., 1998a. Risk analysis of yield losses caused by rice leaf blast associated with temperature changes above and below for five Asian countries. Agric. Ecosys. Environ. 68, 197-205.

Luo, Y., Teng, P.S., Fabellar, N.G., TeBeest, D.O., 1998b. The effects of global temperature change on rice leaf blast epidemics: a simulation study in three agroecological zones. Agric. Ecosys. Environ. 68, 187-196.

Marshall, G., 1999. Herbicide-tolerant crops - real farmer opportunity or potential environmental problem? Pesticide Sci. 52, 394-402.

Mearns, L.O., Gutowski, W., Jones, R., Leung, R., McGinnis, S., Nunes, A., Qian, Y., 2009. A regional climate change assessment program for North America. Eos. Trans. Am. Geophys. U 90, 311.
Mendelsohn, R., Dinar, A., 1999. Climate change, agriculture, and developing countries: does adaptation matter? World Bank Research Obs. 14, 277293.

Motha, R.P., Baier, W., 2005. Impacts of present and future climate change and climate variability on agriculture in the temperate regions: North America. Clim. Change 70, 137-164.

Nakicenovic, N., Swart, R. Eds., 2000. Special Report on Emissions Scenarios: A Specia Report of Working Group III of the Intergovernmental Panel on Climate Change, Cambridge University Press, Cambridge, U.K., 599 pp. Available online at http://www.grida.no/climate/ipcc/emission/index.htm (verified 8 April 2010).

Passioura, J.B., 1996. Simulation models: science, snake oil, education, or engineering? Agron. J. 88, 690-694.

Reilly, J.M., Baethgen, W., Chege, F.E., van de Geijn, S.C., Lin, E., Iglesias, A., Kenny, G., Patterson, D., Rogasik, J., Roetter, R., Rosenzweig, C., Sombroek, W., Westbrook, J., 1996. Agriculture in a changing climate: impacts and adaptation. In: Watson, R.T., Zinyowera, M.C., Moss, R.H. (Eds.), Climate Change 1995 Impacts, Adaptations and Mitigation of Climate Change: Scientific-Technica Analyses-Contribution of Working Group II to the Second Assessment Report of the Intergovernmental Panel on Climate Change. Cambridge University Press, Cambridge, pp. 427-467.

Reynolds, J.F., Acock, B., 1997. Modularity and genericness in plant and ecosystem models: modularity in Plant Models. Ecol. Model. 94, 7-16.

Rosenberg, N.J., Brown, R.A., Izaurralde, R.C., Thomson, A.M., 2003. Integrated assess ment of Hadley Centre (HadCM2) climate change projections on agricultura productivity and irrigation water supply in the conterminous United States: I. climate change scenarios and impacts on irrigation water supply simulated with the HUMUS model. Agric. For. Met. 117, 73-96.

Rosenberg, N.J., Crosson, P.R., Frederick, K.D., Easterling III, W.E., McKenney, M.S. Bowes, M.D., Sedjo, R.A., Darmstadter, J., Katz, L.A., Lemon, K.M., 1993. The MINK methodology: background and baseline. Clim. Change 24, 7-22.

Rosenzweig, C., 1985. Potential $\mathrm{CO}_{2}$-induced climate effects on North American wheat-producing regions. Climatic Change 7, 367-389.

Rosenzweig, C., Tubiello, F.N., 2007: Adaptation and mitigation strategies in agriculture: an analysis of potential synergies. Mitig. Adapt. Strategies Global Change 12, 855-873, doi:10.1007/s11027-007-9103-8.

Rosenzweig, C., Ritchie, J.T., Jones, J.W., Tsuji, G.Y., Hildebrand, P., 1995. Climate change and agriculture: analysis of potential international impacts. American Society of Agronomy, Madison, WI.

Smit, B., Ludlow, L., Brklacich, M., 1988. Implications of a global climatic warming for agriculture: a review and appraisal. J. Environ. Qual. 17, 519-527.

Soussana, J.F., Graux, A.I., Tubiello, F.N., 2010. Improving the use of modelling for projections of climate change impacts on crops and pastures. J. Exp. Bot. 61 2217-2228.

Stokes, C.J., Howden, S.M. 2008. An overview of climate change adaptation in Australian primary industries-impacts, options and priorities. Report prepared for the National Climate Change Research Strategy for Primary Industries, Land and Water Australia, Canberra. p. 344. http://www.csiro.au/files/files/plhg.pdf (verified 13 September 2010).

Tans, P., 2010. Trends in atmospheric carbon dioxide. NOAA/ESRL http://www.esrl.noaa.gov/gmd/ccgg/trends/ (verified 13 September 2010).

Tegart, W.J., McG, Sheldon, G.W., Griffiths, D.C. (Eds.), 1990. Impacts Assessment of Climate Change-Report of Working Group II. Australian Government Publishing Service, Australia.

Thornton, P.K., Hoogenboom, G., 1994. A computer program to analyze single-season crop model outputs. Agron. J. 86, 860-868.

Thornton, P.K., Wilkens, P.W., 1998. Risk assessment and food security. In: Tsuji, G.Y., Hoogenboom, G., Thornton, P.K. (Eds.), Understanding Options for Agricultural Production. Kluwer Academic Publishers, Dordrecht, The Netherlands, pp. 329-345.

Timsina, J., Humphreys, E., 2006. Applications of CERES-rice and CERES-wheat in research, policy and climate change studies in Asia: a review. Int. J. Agric. Res. 1 , $202-225$.

Tsuji, G.Y., Hoogenboom, G., Thornton, P.K. (Eds.), 1998. Understanding Option for Agricultural Production. Kluwer Academic Publishers, Dordrecht, The Netherlands.

Tubiello, F.N., Ewert, F., 2002. Simulating the effects of elevated $\mathrm{CO}_{2}$ on crops: approaches and applications for climate change. Eur. J. Agron. 18, 57-74.

UKCIP, 2010. Previous UK climate information. http://www.ukcip.org.uk/ ukcp09/previous-information (verified 8 April 2011).

Van Ittersum, M.K., Howden, S.M., Asseng, S., 2003. Sensitivity of productivity and deep drainage of wheat cropping systems in a Mediterranean environmen to changes in $\mathrm{CO}_{2}$, temperature and precipitation. Agric. Ecosys. Environ. 97 255-273.

Viner, D., Hulme, M., Raper, S.C.B., 1995. Climate change scenarios for the assessments of the climate change on regional ecosystems. J. Thermal Biol. 20, $175-190$.

White, J.W., Corbett, J.D., Dobermann, A., 2002. Insufficient use of meso-resolution spatial analysis in the planning, execution and dissemination of agronomic research? Field Crops Res. 76, 45-54.

Yuan, J.S., Tiller, K.H., Al-Ahmad, H., Stewart, N.R., Stewart Jr., C.N., 2008. Plants to power: bioenergy to fuel the future. Trends Plant Sci. 13, 421-429. 